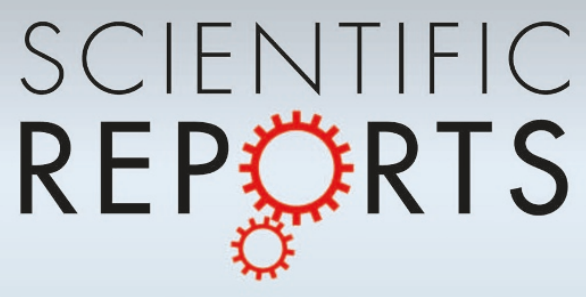

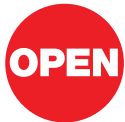

SUBJECT AREAS:

MATERIALS SCIENCE

PHYSICAL CHEMISTRY

NANOSCALE MATERIALS

CONDENSED-MATTER PHYSICS

Received

29 October 2012

Accepted

18 December 2012

Published

28 January 2013

Correspondence and requests for materials should be addressed to Y.T. (takahashi@laser. apph.tohoku.ac.jp)

\section{Parasitic amorphous on single-domain crystal: Structural observations of silicate glass-ceramics}

\author{
Yoshihiro Takahashi, Yoshiki Yamazaki, Rie Ihara \& Takumi Fujiwara
}

Department of Applied Physics, Tohoku University, 6-6-05 Aoba, Aoba-ku, Sendai 980-8579, Japan.

Glass-ceramics (GCs) are materials obtained from the crystallisation of functional phases in glass, and have a structure that the crystallised phase embedded in the glass matrix. Glass-forming oxides are commonly added to the functional phases to improve the stability of precursor glass; however, the issue of glass-ceramics permitting the presence of residual phases resulting from addition is required to be clarified. To elucidate this issue, we prepared 'perfectly surface-crystallised' GC consisting of fresnoite-type $\mathrm{Sr}_{2} \mathrm{TiSi}_{2} \mathrm{O}_{8}$ from a non-stoichiometric glass and performed texture/morphology observations. Numerous $\mathrm{SiO}_{2}$-rich binodal-like nanospheres $(\sim 10 \mathrm{~nm})$ were parasitic on the fresnoite single-crystal domains. The parasitic texture is considered to form via the following process: (i) binodal-type phase separation into stoichiometric fresnoite (crystalline matrix) and $\mathrm{SiO}_{2}$-rich phases (amorphous nanoparticles) and (ii) single-domain formation by surface crystallisation in the matrix. Furthermore, in terms of texture, the resulting GC differs from the GCs reported to date, i.e., inverse GC.

7 lass crystallisation is considered as the ordering process of a random structure that consists of ions or coordinated polyhedra in the supercooled liquid (SCL) regime. Because the glass phase is thermodynamically a non-equilibrium state, it could eventually convert to crystalline phases through structural relaxation by thermal/optical stimulation. The crystallised phases are mainly controlled by the composition of the glass and its short-/medium-range structure. Subsequently, glass-ceramics (GCs) characterised by dispersed crystalline nano or submicron particles, or highly oriented crystalline texture can be obtained ${ }^{1-6}$. Therefore, the production of crystalline materials with glass as the precursor, i.e. GC processing, has been recognised as an effective approach to fabricate functional materials and create nanostructures. Consequently the GC processing has been rigorously investigated with the aim of extending its use to the fabrication of sophisticated materials/ devices in electric, photonic and energy fields $s^{7-12}$. Homogeneous-crystalline slab and line patterning for optical waveguides in glass in combination with special processing have also been realised ${ }^{13-16}$.

To synthesise stable precursor glass, the composition is often selected from systems in which typical glassforming oxides are added to a functional (e.g. ferroelectric) phase, resulting in non-stoichiometric glass. On the other hand, non-stoichiometric precursors possess uniform crystalline domain textures, which is sufficient for light propagation via annealing/laser irradiation ${ }^{11,13,15}$. Although many functional optical-grade GCs have been prepared on the basis of the above procedure, the formation of a dense crystalline texture in non-stoichiometric glass is required to be clarified. If the precursor glass includes excess components such as glass-forming oxides, the residual phase should segregate from the SCL phase in the crystallisation regime, and consequently, the optical transmittance could considerably decrease owing to light scattering at the interface between the crystalline domain and the residual. To elucidate this issue, we prepared 'perfectly surface crystallised (PSC)' GC (PSCGC), in which fresnoite-type $\mathrm{Sr}_{2} \mathrm{TiSi}_{2} \mathrm{O}_{8}$ crystal domains are observed ${ }^{17}$, and conducted micro and nanoscopic investigations of the GC texture.

\section{Results}

Preliminary studies of PSC-GC. Because fresnoite $\left(\mathrm{Ba}_{2} \mathrm{TiSi}_{2} \mathrm{O}_{8}\right)$ and its derivatives (e.g. $\mathrm{Sr}_{2} \mathrm{TiSi}_{2} \mathrm{O}_{8}$ and $\mathrm{Ba}_{2} \mathrm{TiGe}_{2} \mathrm{O}_{8}$ ) are non-centrosymmetric phases with excellent dielectric and optical properties, many researchers devoted time and effort to fabricate fresnoite-type GC and apply them to photonic components ${ }^{11,17-22}$. Recently, Yamazaki et al. demonstrated the fabrication of a GC showing PSC, in which the crystalline domains are aligned along the crystallographic polar $c$-axis by isothermally heat treating a nonstoichiometric precursor glass with $35 \mathrm{SrO}-20 \mathrm{TiO}_{2}-45 \mathrm{SiO}_{2}$ composition ${ }^{17}$. They also demonstrated that 
PSC-GC exhibit optical transmittance comparable to that of the precursor in the visible region. In this study, we followed the published procedures ${ }^{17}$ and were able to obtain a GC sample with good transparency via heat treatment [Fig. 1(a)]. We also confirmed the crystallisation of fresnoite-type $\mathrm{Sr}_{2} \mathrm{TiSi}_{2} \mathrm{O}_{8}$ by X-ray diffraction (XRD) analysis, and the results suggested that the nonstoichiometric precursor is compatible with the reported precursor.

To check the texture of the crystalline domain in the far-field view, we used polarised light microscopy (PLM); the observations revealed a uniform/dense crystalline texture in which fresnoite domains (width: $\sim 5-10 \mu \mathrm{m}$ ) grow from the surface and eventually their growth fronts impinge on each other (one can imagine it as a cross-section of rectangular ice candy) [Fig. 1(b)]. At first, we speculated that the excess component, which could be excluded from the SCL phase, is present in the growth front of the fresnoite domains because of the difference in composition between the SCL and fresnoite phase. If so, the domain growth would cause an accumulation of the excess component, thus disrupting the domain growth. Nevertheless, field-emission (FE) scanning electron microscopy (SEM) with an energy dispersive X-ray fluorescence spectrometer (EDX) analysis revealed no significant variation in the composition along the domain growth [Fig. 1(c)]. Although the composition of the precursor glass is richer in $\mathrm{SiO}_{2}$ than the fresnoite phase, the residual glass phase could not been observed in the polarisation micrograph.

Nanoscopic observations of crystalline domains in PSC-GC. Next, we used field-emission transmission electron microscopy (FE-TEM) to study the texture or morphology within the crystalline domains and investigate the 'missing' residual phase in the domains. Figure 2 shows a typical TEM image of a PSC sample obtained by isothermal crystallisation. The observation geometry is the same as the microscopic observation (Fig. 1), i.e. cross section of the PSC sample. Distinct domain regions (i.e. left and right areas) [Fig. 2(a)] can be observed. From the selected area electron diffraction (SAED) patterns, it was found that the individual regions are fresnoite-type $\mathrm{Sr}_{2} \mathrm{TiSi}_{2} \mathrm{O}_{8}$ single-crystal domains with different crystal zone axes, i.e. $B=\left[\begin{array}{lll}1 & 1 & 0\end{array}\right]$ and $B=\left[\begin{array}{lll}1 & 2 & 0\end{array}\right]$ for the left and right domains, respectively, [Fig. 2(b) and (c)]; thus, the single-crystal domains grow along the polarisation $c$-axis. In addition, 'white spots' having a diameter of $\sim 10-20 \mathrm{~nm}$ distributed over a single domain can be observed, which resembles binodal liquid-liquid phase separation. Furthermore, the SAED of such a spot exhibited a halo pattern, which is characteristic of amorphous phases [Fig. 2(d) and (e)]. Because the increase in the atomic number of the constituent elements decreased the intensity of the transmitting electrons, we deduced that the binodal-like nanoparticles mainly consist of lighter elements such as Si. From the TEM-EDX analysis, we detected $\mathrm{Si}$, Ti and $\mathrm{Sr}$ (constituents of the fresnoite-type $\mathrm{Sr}_{2} \mathrm{TiSi}_{2} \mathrm{O}_{8}$ ) in the surrounding single-crystal region [Fig. 2(d), point A], while the signal intensity of $\mathrm{Sr}(\mathrm{Sr} \mathrm{K} \alpha$ and $\mathrm{Sr} \mathrm{K} \beta$ ) was hardly observed in the nanoparticle (point B) [Fig. 2(f)]. This means that the Sr abundance ratio of the particle is relatively less than that of the single domain. Both TEM and ED analyses strongly suggest that binodal-type phase separation, which provided the $\mathrm{SiO}_{2}$-enriched nanoparticles, occurred in the SCL regime before the crystallisation of the fresnoite phase.

According to Baylor and Brown ${ }^{23}$, a large stable two-liquid region (i.e. opaque glass) is present in the ternary $\mathrm{SrO}-\mathrm{B}_{2} \mathrm{O}_{3}-\mathrm{SiO}_{2}$ system between the stable immiscible regions of the $\mathrm{SrO}-\mathrm{SiO}_{2}$ and $\mathrm{SrO}-\mathrm{B}_{2} \mathrm{O}_{3}$ joins. In addition, in the vicinity of stable-immiscibility boundary, the transparent glass (i.e. one-liquid region) had dispersed $\mathrm{SiO}_{2}$-rich nanoparticles embedded in a SrO-rich glass matrix presumably because of metastable immiscibility. We find that the morphological features resemble those of PSC-GC in the $\mathrm{SrO}-\mathrm{TiO}_{2}-\mathrm{SiO}_{2}$ system. Therefore, we examined the approximate immiscible and glass-forming regions and discussed the phase separation trend in the ternary system. We examined 55 compositions and found the following features (Fig. 3): i) for $\mathrm{SiO}_{2}$ content $>30 \mathrm{~mol} \%$, the stable-immiscible region in the ternary system is considerably similar to that of the $\mathrm{SrO}-\mathrm{B}_{2} \mathrm{O}_{3}-\mathrm{SiO}_{2}$ system, i.e. there is a large two-liquid region below the $\sim 25 \mathrm{~mol} \% \mathrm{SrO}$ isopleth. Because the $\mathrm{TiO}_{2}-\mathrm{SiO}_{2}$ and $\mathrm{B}_{2} \mathrm{O}_{3}-\mathrm{SiO}_{2}$ joins have a large twophase liquid region ${ }^{24}$, it is reasonable to assume that the ternary $\mathrm{SrO}-\mathrm{B}_{2} \mathrm{O}_{3}-\mathrm{SiO}_{2}$ and $\mathrm{SrO}-\mathrm{TiO}_{2}-\mathrm{SiO}_{2}$ systems exhibit immiscibility or phase-separation; and ii) for $\mathrm{SiO}_{2}<30 \mathrm{~mol} \%$, the immiscible region decreased towards the $\mathrm{SrO}-\mathrm{TiO}_{2}$ join, probably due to the decrease in the glass former.
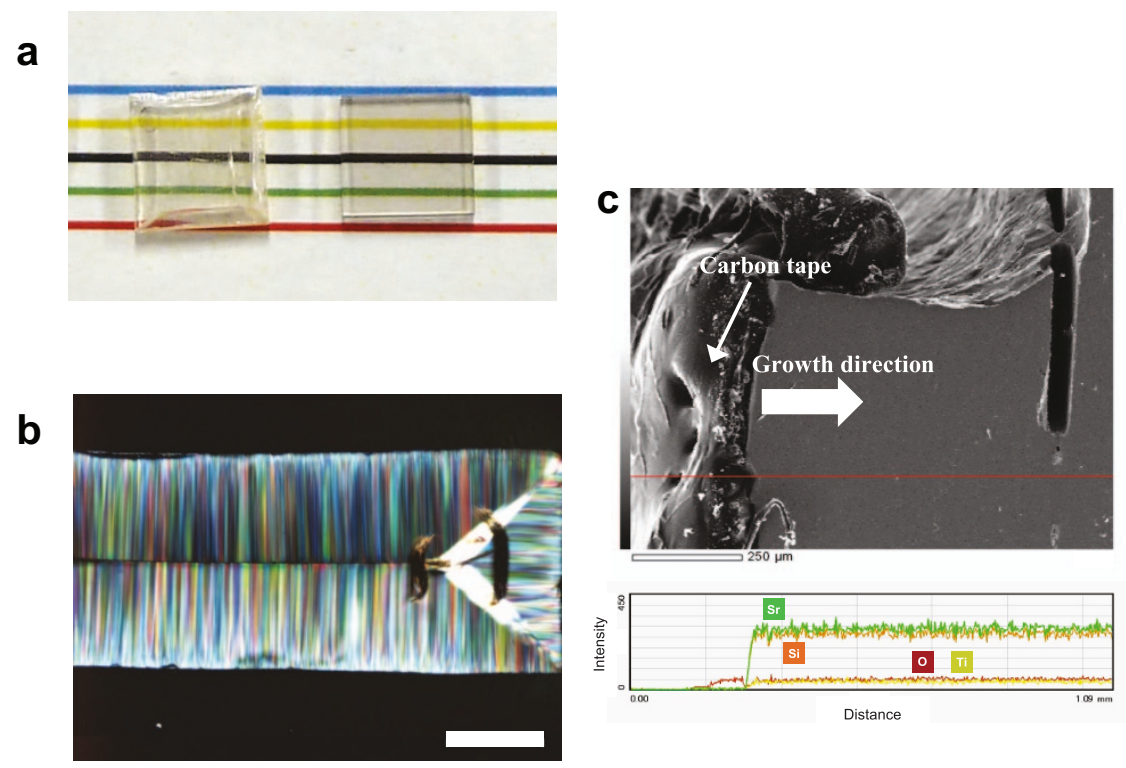

Figure 1 Macro and microscopic observations of GC samples. (a) Appearance of GC (left) and its precursor glass (right). The GC sample was prepared on the basis of the report by Yamazaki et al. (b) Polarised light micrograph of the cross-section for the GC obtained at $940^{\circ} \mathrm{C}$ for $3 \mathrm{~h}$. White bar corresponds to $0.5 \mathrm{~mm}$. (c) SEM image (above) and EDX line analysis for Sr, Ti and Si (bottom) in the cross-section of PSC-GC. Red line corresponds to the scanned position. 
a

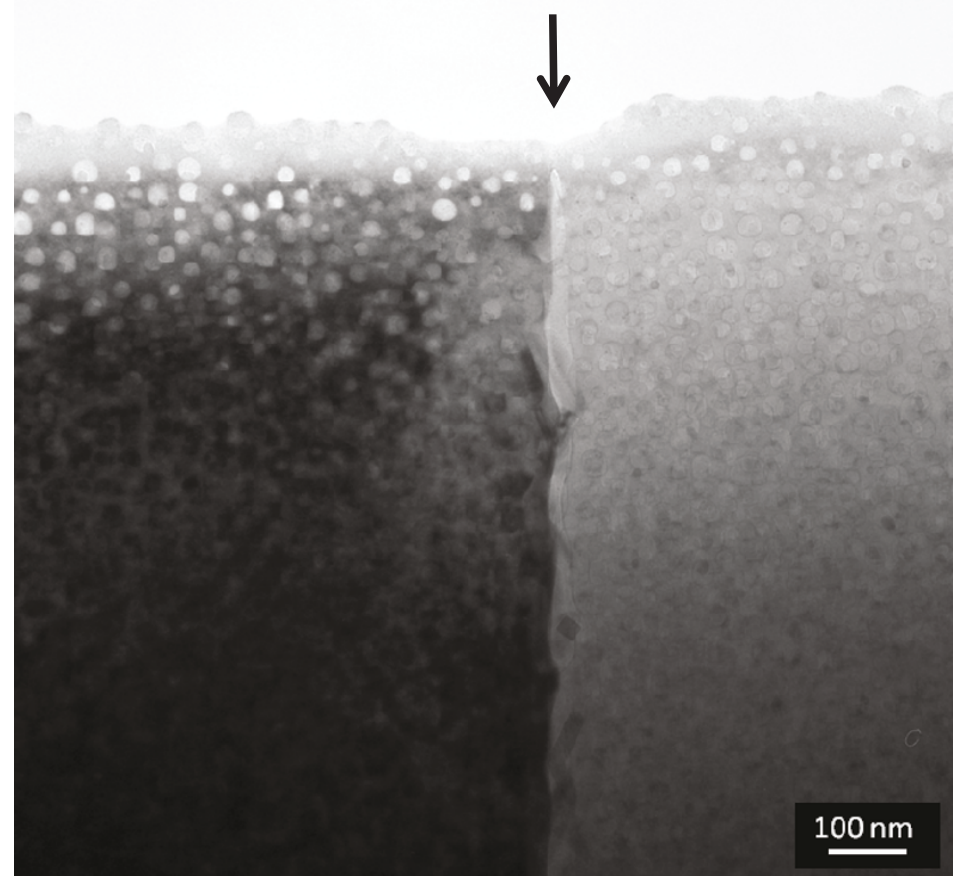

d

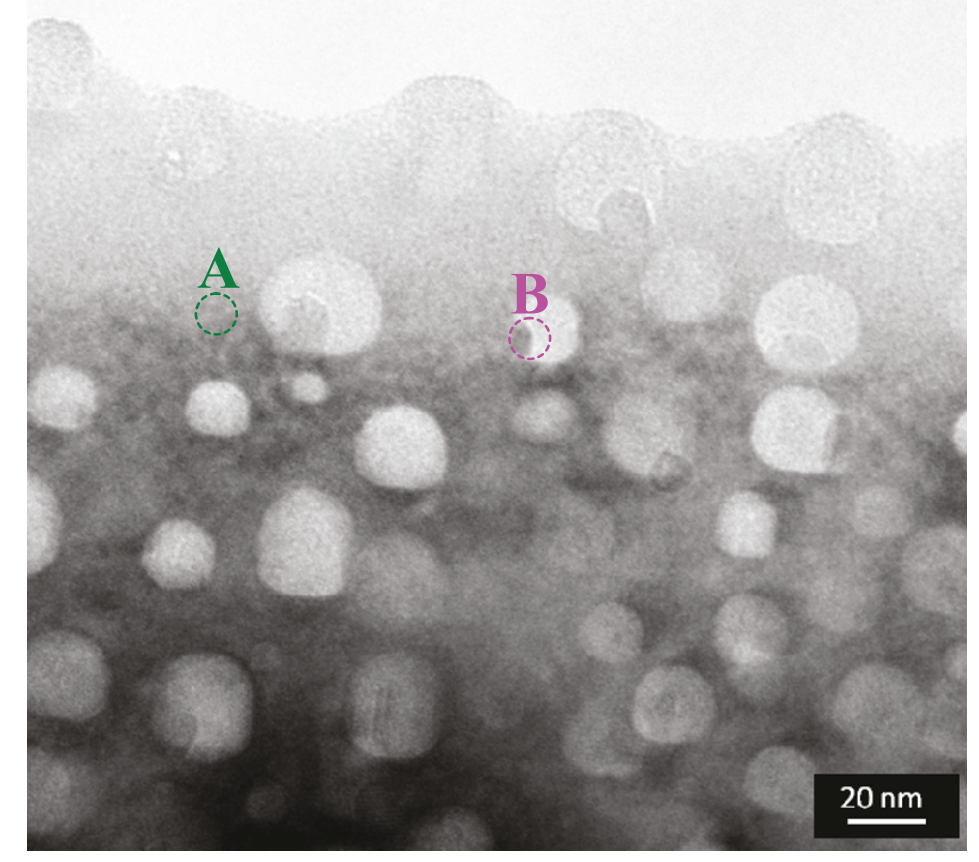

b

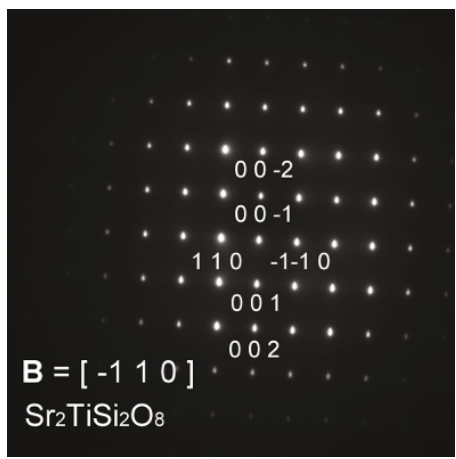

C

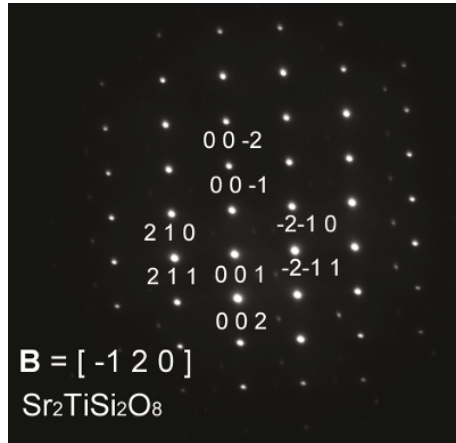

e
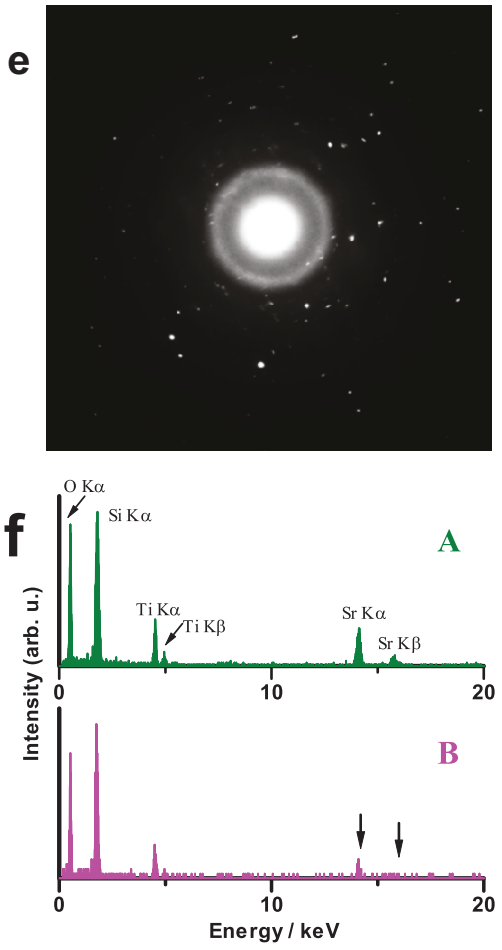

Figure $2 \mid$ Nanoscopic observations of the crystalline domain of the PSC sample. (a) TEM image of the PSC sample obtained at $1000^{\circ} \mathrm{C}$ for 1 h. Arrow indicates the crystalline domain boundary. The geometry is the same as that in the microscopic observation (cross-section). (b) SAED pattern of the leftside domain (dark region) and (c) the right-side domain (bright region). The SAED patterns revealed single-crystal features that were identified as fresnoite-type $\mathrm{Sr}_{2} \mathrm{TiSi}_{2} \mathrm{O}_{8}$ with different crystal zone axes. (d) Near-field TEM image. (e) SAED pattern of the binodal-like nanoparticles with the typical halo pattern, i.e. amorphous phase. (f) EDX spectra of the surrounding region (single-crystal domain, A) and nanoparticle (amorphous, B). At point B, the chemical abundance of Sr was relatively low (indicated by the arrows) compared with the single-domain region.

\section{Discussion}

In terms of the $\mathrm{SrO}-\mathrm{TiO}_{2}-\mathrm{SiO}_{2}$ system, the analogy in the phaseseparation morphology and immiscibility lead us to expect that an immiscible region also extends into the one-liquid region (from which the transparent samples were obtained) near the boundary below the liquidus temperature (metastable immiscibility). The composition of the precursor glass for PSC-GC is also situated near this boundary. Considering the phase-separation trend in the aforementioned one-liquid region ${ }^{23}$, and because the resulting PSC-GC crystallises single-phase fresnoite, the precursor glass in the SCL state 


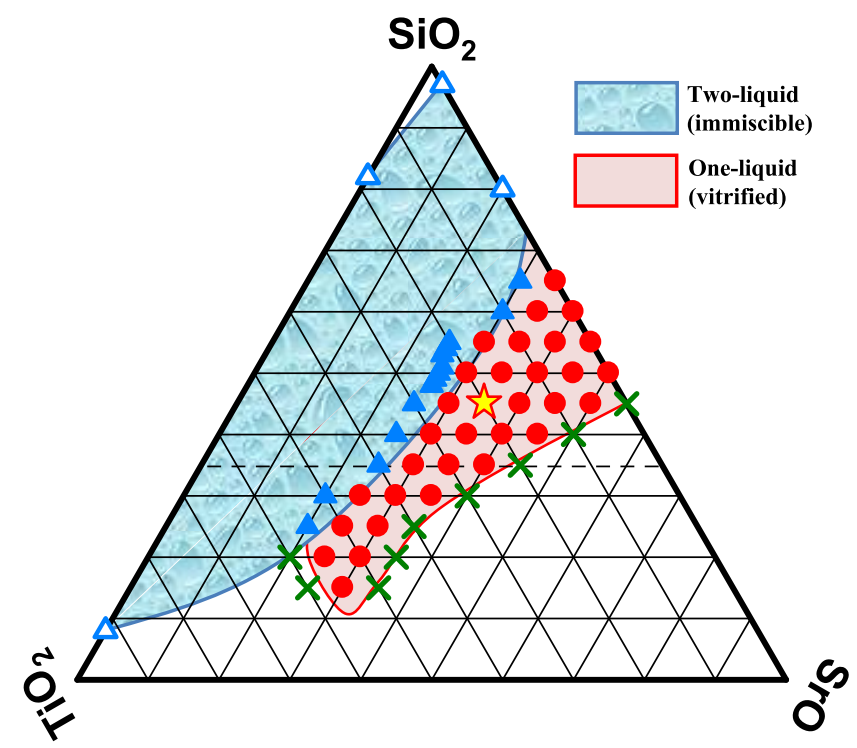

Figure $3 \mid$ Glass-forming and approximate two-liquid regions in the $\mathrm{SrO}-\mathrm{TiO}_{2}-\mathrm{SiO}_{2}$ system. Closed and crossed symbols correspond to the examined compositions. Triangle: phase separated, circle: transparent glass and cross: devitrified. Star symbol shows the composition of PSC-GC, i.e. $35 \mathrm{SrO}-20 \mathrm{TiO}_{2}-45 \mathrm{SiO}_{2}$. Open triangles in the $\mathrm{TiO}_{2}-\mathrm{SiO}_{2}$ and $\mathrm{SrO}-\mathrm{SiO}_{2}$ joins correspond to the points where a two-liquid phase is reported by DeVries et al. and Fields, Jr. et al., respectively. Dashed line across the diagram represents the lower limit of the glass-forming region in terms of $\mathrm{SiO}_{2}$, which was reported by Imaoka and Yamazaki. We found a large glass-forming region that extends to the low- $\mathrm{SiO}_{2}$ compositions.

could separate into a SrO-rich phase, which corresponds to the fresnoite stoichiometry $\left(\mathrm{Sr}_{2} \mathrm{TiSi}_{2} \mathrm{O}_{8}\right)$ and a residual $\mathrm{SiO}_{2}$-rich phase. This may be expressed by the following formula,

$35 \mathrm{SrO}-20 \mathrm{TiO}_{2}-45 \mathrm{SiO}_{2} \rightarrow 35 \mathrm{SrO}-17.5 \mathrm{TiO}_{2}-35 \mathrm{SiO}_{2}$ (stoichiometric, surrounding matrix) $+2.5 \mathrm{TiO}_{2}-10 \mathrm{SiO}_{2}$ (residual, nanoparticle).

Although the formula indicates an ideal case so that the phaseseparation trend should be examined more in detail, the trend is supported by the TEM studies (EDX and ED analyses) in this study. Furthermore, we also showed that the glass-forming region is considerably extended to the high- $\mathrm{TiO}_{2}$ ( or low- $\mathrm{SiO}_{2}$ ) region when compared with the region reported by Imaoka and Yamazaki ${ }^{25}$. In the glass-forming region in their study, the compositions with $<30 \mathrm{~mol} \% \mathrm{SiO}_{2}$ did not vitrify ${ }^{25}$, while in the present study, we could obtain the $30 \mathrm{SrO}-55 \mathrm{TiO}_{2}-15 \mathrm{SiO}_{2}$ glass. This indicates the necessity to reconsider the conventional glass-forming diagram, in which the intermediate oxide $\left(\mathrm{TiO}_{2}\right.$ in this case) is largely included.

From the experimental results and the discussion above, the possible scenario for the precursive stage of PSC is as follows:

(a) As the temperature increases above the glass-transition temperature at which the glass state changes to the SCL state, the constituent atoms acquire adequate fluidity for two-liquid phase separation caused by metastable immiscibility and results in binodal-like nanoparticles and the surrounding SCL phase.

(b) The formation of the $\mathrm{SiO}_{2}$-rich nanoparticles causes the SCL matrix composition to approach that of stoichiometric $\mathrm{Sr}_{2} \mathrm{TiSi}_{2} \mathrm{O}_{8}$, thus establishing the conditions for the crystallisation of the fresnoite phase.

(c) With further increase in the temperature at which inhomogeneous nucleation occurs, the SCL matrix is transformed into the fresnoite crystal domains due to surface crystallisation. During the domain growth, the already settled binodal-like nanoparticles are captured at the fresnoite growth front and consequently, the nanoparticles are frozen in the domains, result in 'crystal domains parasitised by amorphous nanoparticles'. Surface crystallisation often exhibits a strongly oriented texture originating from competitive crystal growth of nuclei generated on the glass surface based on geometrical selection ${ }^{26}$. This mechanism can be adopted to explain the orientation of the $c$-axis in PSC-GC as well.

Wisniewski et al. recently reported the surface crystallisation of fresnoite-type $\mathrm{Sr}_{2} \mathrm{TiSi}_{2} \mathrm{O}_{8}$ in $\mathrm{SiO}_{2}$-enriched non-stoichiometric glass, in which the opaque GCs exhibited excellent piezoelectric properties owing to the strong orientation of the texture ${ }^{27,28}$. This research group has also attempted to explain residual $\mathrm{SiO}_{2}$ using electron backscatter diffraction and SEM and predicted the presence of $\mathrm{SiO}_{2}$-rich structure at the nanoscale (i.e. nanoporous with channels similar to sponge $)^{27}$. Our study validates this idea; however, the nanostructure in their study is apparently different from that in our study (i.e. binodal nanoparticle). This difference is presumably attributed to the difference in glass composition (i.e. $34.8 \mathrm{SrO}-17.4 \mathrm{TiO}_{2}-$ $47.8 \mathrm{SiO}_{2}$ by Wisniewski et $\mathrm{al}^{27}$. and $35 \mathrm{SrO}-20 \mathrm{TiO}_{2}-45 \mathrm{SiO}_{2}$ by Yamazaki et $\mathrm{al}^{17}$.), thus suggesting that nanostructures are sensitive to variation in the composition.

Basically, the transparency of GC materials depends on two factors. According to Beall and Duke, the intensity of the light is described on the basis of Rayleigh scattering by the following equation,

$$
I(\theta)=\frac{\left(1+\cos ^{2} \theta\right)}{r^{2}} \frac{8 \pi^{4}}{\lambda^{4}} a^{6}\left(\frac{M^{2}-1}{M^{2}+2}\right) I_{0},
$$

where $I$ is the intensity of the scattered light, $\theta$ is the scattering angle, $r$ is the distance from the scattering source, $\lambda$ is the wavelength of the light, $a$ is the radius of the particle in the matrix, $M$ is the ratio of the refractive index of the particle to that of the matrix and $I_{0}$ is the intensity of the incident light ${ }^{29}$. From Eq. (1), either the smallness of the crystals in the glass matrix (i.e. nanocrystallisation: $a \ll \lambda$ ) or the closeness of the refractive index of the crystals to that of the matrix (refractive matching; $M \sim 1$ ) is chosen. Nanocrystallisation can be used to reliably prepare precursor glass which would be transparent in the visible wavelength even if there is a significant difference in the refractive index between the glass matrix and the crystallised nanoparticles; GCs consisted of multi-component glass and $\mathrm{Nb}$-ferroelectrics is a typical example ${ }^{30,31}$. On the other hand, the PSC-GC sample in this study is constructed by single-domain fresnoite in the matrix and parasitic nanoparticles $(\sim 10-20 \mathrm{~nm})$, which correspond to the residual $\mathrm{SiO}_{2}$-rich amorphous phase. Phase separation typically makes glass opalescent because of the structure developed at the scale of the visible wavelength by spinodal or binodal decomposition. However, the size of the parasitic nanoparticles is significantly less than the visible wavelength, indicating that light scattering is minimised. Thus, we demonstrated a method to fabricate 'inverse GC', in which the texture is completely reversed. Furthermore, the study of inverse GC also provides significant insight into single-crystal line patterning using laser processing ${ }^{13-15,32}$ because this study clarifies the location of the residual phase after single-line formation.

\section{Methods}

Preparation of glass and PSC samples. The glass samples we dealt with belonged to the ternary $\mathrm{SrO}-\mathrm{TiO}_{2}-\mathrm{SiO}_{2}$ system and were prepared by using the conventional melt-quenching technique. Commercial powders of reagent grade $\mathrm{SrCO}_{3}(99.9 \%$ purity), $\mathrm{TiO}_{2}(99.99 \%)$ and $\mathrm{SiO}_{2}(99.9 \%)$ were weighed and mixed. Then, the mixture was melted in a platinum crucible covered with a lid at $1350-1600^{\circ} \mathrm{C}$ (the temperature condition depends on the composition) for $1 \mathrm{~h}$ in air. For example,

$35 \mathrm{SrO}-20 \mathrm{TiO}_{2}-45 \mathrm{SiO}_{2}$ glass, which indicates PSC, was obtained at $1500^{\circ} \mathrm{C}$. The melt was poured onto a steel plate $\left(\sim 200^{\circ} \mathrm{C}\right)$ and pressed with another steel plate. The as-quenched (amorphous) samples were annealed around the glass-transition 
temperature $\left(T_{\mathrm{g}} \sim 760^{\circ} \mathrm{C}\right)$ for $1 \mathrm{~h}$ to reduce internal stresses. The annealed samples were polished to get a mirror surface and then cut into several pieces with dimensions of $\sim 10 \mathrm{~mm} \times 10 \mathrm{~mm} \times 1 \mathrm{~mm}$. To fabricate PSC-GC, the precursor glass was subjected to isothermal heat treatment at appropriate temperatures $\left(\sim 900-1000^{\circ} \mathrm{C}\right)$ in an electric furnace in air.

Characterisation of the glass and GC samples. The precursor glass was characterised by differential thermal analysis (bulk state, $10^{\circ} \mathrm{C} / \mathrm{min}$ heating rate) and $\mathrm{XRD}$. In addition, XRD was used to identify the crystalline phase in the PSC-GC samples. We also used PLM, FE-SEM with EDX (JEOL, JSM-6500F) and FE-TEM with EDX (Hitachi, HF-2000) to characterise the crystallised fresnoite-phase. To determine the glass-forming region in the ternary system, the as-quenched samples were examined (i) by powder X-ray diffraction (XRD) using $\mathrm{Cu} K \alpha$ radiation to determine whether the samples were amorphous and (ii) optically to clarify two-liquid phase (opaque/ white) or one-liquid phase (transparent) (Fig. 3).

1. Borrelli, N. F., Herczog, A. \& Maurer, R. D. Electro-optic effect of ferroelectric microcrystals in a glass matrix. Appl. Phys. Lett. 7, 117-118 (1965).

2. Majumdar, A. J., Nurse, R. W., Chatterii, S. \& Jeffrey, J. W. Three-dimensional view of phase separation in glass ceramics. Nature 211, 622-624 (1966).

3. Pinckney, L. R. \& Beall, G. H. Nanocrystalline non-alkali glass-ceramics. J. NonCryst. Solids 219, 219-227 (1997).

4. Rüssel, C. Oriented crystallization of glass. A review. J. Non-Cryst. Solids 219, 212-218 (1997).

5. Jain, H. Transparent ferroelectric glass-ceramics. Ferroelectr 306, 111-127 (2004).

6. Cabral, A. A., Fokin, V. M. \& Zanotto, E. D. Nanocrystallization of fresnoite glass. II. Analysis of homogeneous nucleation kinetics. J. Non-Cryst. Solids 343, 85-90 (2004).

7. Halliyal, A., Bhalla, A. S., Newnham, R. E. \& Cross, L. E. Piezoelectric properties of lithium borosilicate glass ceramics. J. Appl. Phys. 53, 2871-2874 (1982).

8. Ding, Y. et al. Lithium disilicate crystalline slab waveguides from surface crystallized glass. Electron. Lett. 35, 504-505 (1999).

9. Rosenflanz, A. et al. Bulk glasses and ultrahard nanoceramics based on alumina and rare-earth oxides. Nature 430, 761-764 (1999).

10. Murugan, G. S. \& Varma, K. B. R. Dielectric, linear and non-linear optical properties of lithium borate-bismuth tungstate glasses and glass-ceramics. J. NonCryst. Solids 279, 1-13 (2001).

11. Iwafuchi, N., Hirokazu, M., Takahashi, Y. \& Fujiwara, T. Electro-optic measurement in glass ceramics with highly oriented crystalline layers. Electron. Lett. 46, 69-71 (2010).

12. Hayashi, A., Noi, K., Sakuda, A. \& Tatsumisago, M. Superionic glass-ceramic electrolytes for room-temperature rechargeable sodium batteries. Nat. Commun. 3, 856, doi: $10.1038 /$ ncomms1843 (2012).

13. Himei, Y., Ding, Y., Ikebe, M. \& Miura, $\mathrm{Y} . \mathrm{Ca}_{2} \mathrm{Al}_{2} \mathrm{SiO}_{7}$ crystalline slab waveguides from surface crystallized glass. J. Ceram. Soc. Japan 109, 474-476 (2001).

14. Komatsu, T. \& Honma, T. Laser-induced line patterning of nonlinear optical crystals in glass. IEEE J. Select. Top. Quantum Electron. 14, 1289-1297 (2008).

15. Honma, T. \& Komatsu, T. Patterning of two-dimensional planar lithium niobate architectures on glass surface by laser scanning. Opt. Express 18, 8019-8024 (2010)

16. Stone, A. et al. Formation of ferroelectric single-crystal architectures in $\mathrm{LaBGeO}_{5}$ glass by femtosecond vs. continuous-wave lasers. J. Non-Cryst. Solids 356, 3059-3065 (2010).

17. Yamazaki, Y., Takahashi, Y., Ihara, R. \& Fujiwara, T. Surface crystallization of fresnoite-type crystallized glasses with large thickness. J. Ceram. Soc. Japan 119, 757-762 (2011).

18. Takahashi, Y., Benino, Y., Fujiwara, T. \& Komatsu, T. Optical second order nonlinearity of transparent $\mathrm{Ba}_{2} \mathrm{TiGe}_{2} \mathrm{O}_{8}$ crystallized glasses. Appl. Phys. Lett. 81, 223-225 (2002).
19. Takahashi, Y., Benino, Y., Fujiwara, T. \& Komatsu, T. Large second-order optical nonlinearities of fresnoite-type crystals in transparent surface-crystallized glasses. J. Appl. Phys. 95, 3503-3508 (2004).

20. Takahashi, Y., Kitamura, K., Benino, Y., Fujiwara, T. \& Komatsu, T. Second-order optical nonlinear and luminescent properties of $\mathrm{Ba}_{2} \mathrm{TiSi}_{2} \mathrm{O}_{8}$ nanocrystallized glass. Appl. Phys. Lett. 86, 091110 (2005).

21. Zhu, B. et al. Greatly enhanced effect of silver on femtosecond laser-induced precipitation of nonlinear optical crystals in glasses. Opt. Lett. 34, 1666-1668 (2009).

22. Müller, A. et al. Fresnoite thin films grown by pulsed laser deposition: photoluminescence and laser crystallization. Cryst. Eng. Comm. 13, 6377-6385 (2011).

23. Baylor, R. Jr. \& Brown, J. Jr. Phase separation of glasses in the system $\mathrm{SrO}-\mathrm{B}_{2} \mathrm{O}_{3}-\mathrm{SiO}_{2}$. J. Am. Ceram. Soc. 59, 131-136 (1976).

24. DeVries, R. C., Roy, R. \& Osborn, E. F. The system $\mathrm{TiO}_{2}-\mathrm{SiO}_{2}$. Trans. Bri. Ceram. Soc. 53, 525-540 (1954).

25. Imaoka, M. \& Yamazaki, T. Glass-formation ranges of ternary systems (Part 1) silicates of $a$-group elements. Rep. Inst. Ind. Sci. Univ. Tokyo. 18, 240-273 (1968).

26. Takahashi, Y., Saitoh, K., Benino, Y., Fujiwara, T. \& Komatsu, T. Formation of $\mathrm{Ba}_{2} \mathrm{TiGe}_{2} \mathrm{O}_{8}$ phase in $\mathrm{BaO}-\mathrm{TiO}_{2}-\mathrm{GeO}_{2}$ glasses and their optical nonlinearities. J. Non-Cryst. Solids 345, 412-416 (2004).

27. Wisniewski, W., Patschger, M. \& Rüssel, C. Sr-fresnoite surface crystallisation in a $2 \mathrm{SrO} \cdot \mathrm{TiO}_{2} \cdot 2.75 \mathrm{SiO}_{2}$ glass studies by EBSD. Cryst. Eng. Comm. 14, 5425-5433 (2012).

28. Patschger, M., Wisniewski, W. \& Rüssel, C. Piezoelectric glass-ceramics produced via oriented growth of $\mathrm{Sr}_{2} \mathrm{TiSi}_{2} \mathrm{O}_{8}$ fresnoite: thermal annealing of surface modified quenched glasses. Cryst. Eng. Comm. 14, 7368-7373 (2012).

29. Beall, G. H. \& Duke, D. A. Transparent glass-ceramics. J. Mater. Sci. 4, 340-352 (1969).

30. Ahamad, M. N. \& Varma, K. B. R. Structural and optical properties of (100-x) $\mathrm{Li}_{2} \mathrm{~B}_{4} \mathrm{O}_{7} \cdot \mathrm{x}\left(\mathrm{Ba}_{5} \mathrm{Li}_{2} \mathrm{Ti}_{2} \mathrm{Nb}_{8} \mathrm{O}_{30}\right)$ glasses and glass nanocrystal composites. Dalton Trans. 39, 4624-4630 (2010)

31. Takahashi, Y., Fujie, N. \& Fujiwara, T. Nano-sized $\mathrm{Ba}_{2} \mathrm{NaNb}_{5} \mathrm{O}_{15}-\mathrm{NaNbO}_{3}$ co-crystallized glass-ceramics in phosphoniobate system. Appl. Phys. Lett. 100, 201907 (2012).

32. Honma, T., Benino, Y., Fujiwara, T., Komatsu, T. \& Sato, R. Technique for writing of nonlinear optical single-crystal lines in glass. Appl. Phys. Lett. 83, 2796-2798 (2003).

\section{Acknowledgements}

This study was supported by the Ministry of Education, Culture, Sports, Science and Technology of the Japanese Government. We would like to thank Dr. Takamichi Miyazaki of Department of Instrumental Analysis, School of Engineering, Tohoku University for his significant contributions to this study.

\section{Author contributions}

Y. Y. and R. I. performed the fabrication and characterisation of materials. Y. T. and T. F. designed the study, analyzed the data and prepared the paper.

\section{Additional information}

Competing financial interests: The authors declare no competing financial interests. License: This work is licensed under a Creative Commons

Attribution-NonCommercial-NoDerivs 3.0 Unported License. To view a copy of this license, visit http://creativecommons.org/licenses/by-nc-nd/3.0/

How to cite this article: Takahashi, Y., Yamazaki, Y., Ihara, R. \& Fujiwara, T. Parasitic amorphous on single-domain crystal: Structural observations of silicate glass-ceramics. Sci. Rep. 3, 1147; DOI:10.1038/srep01147 (2013). 